\title{
PERSPECTIVAS DA INTEGRAÇÃO REGIONAL LABORAL NO MERCOSUL ANTE OS REVESES NA PROTEÇÃO AO TRABALHO DIGNO
}

\author{
PERSPECTIVES OF REGIONAL LABOR INTEGRATION IN MERCOSUR TOWARDS \\ REVISIONS IN PROTECTING DECENT LABOR
}

Juliane Caravieri Martins ${ }^{1}$

Universidade Federal de Uberlândia

\begin{abstract}
Resumo: a integração regional no MERCOSUL não pode mais se limitar a questões comerciais, devendo incluir temas laborais no intuito de reduzir as assimetrias do desenvolvimento econômico. O objetivo desta pesquisa é demonstrar que o retorno da direita conservadora em países mercosulistas está impulsionando o desmonte dos direitos laborais, impossibilitando a continuidade da agenda social no bloco que foi impulsionada pelo regionalismo pós-liberal. São complexos os fatores que envolvem a questão do trabalho assalariado na América Latina, sendo necessário o "transbordamento" do desenvolvimento econômico para as áreas sociais, principalmente envolvendo o labor humano e a migração de trabalhadores. Se o MERCOSUL não priorizar as relações de trabalho, o projeto integracionista não se efetivará em sua plenitude, podendo esvanecer nas próximas décadas.
\end{abstract}

Palavras-chave: América Latina; integração regional; trabalho digno; MERCOSUL.

Abstract: Regional integration in MERCOSUR can no longer be limited to trade issues, but must include labor issues in order to reduce the asymmetries of economic development. The aim of this research is to demonstrate that the return of the conservative right in mercosurist countries is driving the dismantling of labor rights, making it impossible to continue the social agenda in the bloc that was driven by postliberal regionalism. The factors that involve the issue of wage labor in Latin America are complex, requiring the "spillover" of economic development to social areas, especially involving human labor and worker migration. If MERCOSUR does not prioritize labor relations, the integrationist project will not be fully implemented and may fade in the coming decades.

Keywords: Latin America; regional integration; decent labor; MERCOSUR.

\footnotetext{
1 Professora Adjunta na Universidade Federal de Uberlândia. Doutora em Direito Político e Econômico pela Universidade Presbiteriana Mackenzie, Doutora em Ciências da Integração da América Latina pela Universidade de São Paulo e Mestra em Direito Constitucional pela Pontifícia Universidade Católica de São Paulo. ORCID: http://orcid.org/0000-0001-8784-7914.E-mail: jcaravieri@ufu.br.
} 


\section{INTRODUÇÃO}

Na América Latina, grande parte dos trabalhadores está submetida a intenso processo de exploração de sua mão de obra, usufruindo de péssimas condições de trabalho. Todavia, esta situação não é nova, pois a condição atual do trabalho assalariado na América Latina também é reflexo de seu passado de colônias de exploração econômica quando, a partir do século XV, Espanha e Portugal ocuparam as terras americanas. Fixados a oeste do marco imaginário do Tratado de Tordesilhas, os espanhóis se dedicarem à extração de metais preciosos. Já os portugueses implantaram nas terras a leste a produção açucareira em latifúndios financiados pelos capitais holandeses e com o uso de mão de obra escrava africana.

Em fins do século XIX, o trabalho escravo na Europa já não era mais utilizado em razão do liberalismo econômico e do capitalismo industrial que passaram a fazer uso do trabalho "livre" assalariado e necessitavam da ampliação de mercados consumidores para os produtos manufaturados. Logo, o assalariamento do trabalho "livre" nos países latino-americanos ganhou preponderância com a transição do capitalismo escravista-mercantil e agrário-exportador diretamente para o capitalismo urbano-industrial periférico em fins do século XIX e início do século XX (PIRES; COSTA, 2010).

Sobretudo a partir da eclosão da Segunda Guerra Mundial, a América Latina passou a abastecer o comércio internacional com suas matérias-primas e mão de obra baratas, inserindose na "nova" divisão internacional do trabalho ${ }^{2}$ que lhe era prejudicial e favorável apenas às economias dos países industrializados, sendo denunciada em estudos da Comissão Econômica para a América Latina e o Caribe (CEPAL) ${ }^{3}$.

No pensamento cepalino da década de 1950, destacou-se o estudo "O Mercado Comum Latino-Americano" (1959) de Raúl Prebisch que, ciente das limitações da industrialização substitutiva de importações (ISI), apontou a necessidade de se desenvolver um mercado comum

\footnotetext{
2 A divisão internacional do trabalho passou por diferentes etapas acompanhando o desenvolvimento histórico do capitalismo, iniciando com relações mercantilistas que marcaram o comércio entre metrópoles europeias e colônias de exploração, latino-americanas principalmente, até a configuração de relações entre países, chamados desenvolvidos, e outros considerados subdesenvolvidos ou periféricos no âmbito do capitalismo global.

3 Tendo como expoentes Raúl Prebisch e Celso Furtado em seus primeiros tempos, o pensamento cepalino fundamentou-se numa teoria histórico-estruturalista que analisou o subdesenvolvimento dos países latinoamericanos a partir da ideia do estabelecimento de relações entre países centrais e periféricos no comércio mundial. Tal pensamento se alicerçou, basicamente, nas seguintes diretrizes analíticas: enfoque histórico-estruturalista baseado na ideia de relação centro-periferia; análise da inserção internacional, principalmente no comércio, da América Latina; análise das condicionantes estruturais internas de cada país e estudo das necessidades e possibilidades de ação estatal em cada país para superar o subdesenvolvimento (BIELSCHOWSKY, 2000, p. 1819).
} 
latino-americano no intuito de dinamizar o desenvolvimento econômico da região (BIELSCHOWSKY, 2000, p. 358-359). Assim, foram lançadas as bases do velho regionalismo que influenciou a criação, em 1960, da Associação Latino-Americana de Livre Comércio (ALALC) que foi sucedida, em 1980, pela Associação Latino-Americana de Integração (ALADI).

Sob o marco jurídico da ALADI, o Mercado Comum do Sul (MERCOSUL) assumiu a condição de acordo de alcance parcial, sendo oriundo do Acordo de Complementação Econômica $(A C E) n^{\circ} 18$ a fim de estabelecer condições para a criação de mercado comum nos termos do Tratado de Assunção (1991). Entretanto, é imperiosa a ampliação da agenda integracionista para além dos aspectos meramente comerciais a fim de incluir outras temáticas, principalmente os aspectos sociais e laborais. Ocorre que, atualmente, o MERCOSUL está passando por grave crise institucional decorrente de diversos acontecimentos, ameaçando a integração regional laboral.

A Organização Internacional do Trabalho (OIT) enfatizou, na Declaração de Filadélfia (1944), que o trabalho não é uma mercadoria (art. I) (USP, 2019). Como Brasil, Argentina, Paraguai, Uruguai e Venezuela são Estados-membros da OIT, logo, comprometerem-se com suas normas em prol do direito humano ao trabalho digno. Porém, na América Latina, o desmonte dos direitos laborais vem se agravando nas últimas décadas em razão de governos alinhados com a globalização neoliberal.

Os governos de "esquerda" nos países latino-americanos se perderam numa série de escândalos de corrupção, possibilitando o retorno da direita conservadora no continente que está impulsionando o desmonte dos direitos sociais laborais, impossibilitando a continuidade da agenda social no bloco mercosulista impulsionada pelo regionalismo pós-liberal. Então, questiona-se se os preceitos e diretrizes da OIT para o trabalho digno estão sendo efetivamente implementados no MERCOSUL. Como metodologia científica, a pesquisa utilizou o método dialético e, quanto à técnica de pesquisa, utilizou-se a bibliográfica-exploratória.

Assim, o presente estudo dividiu-se em duas partes. Primeiramente, buscou-se analisar a concepção de trabalho digno no sistema internacional de proteção aos direitos humanos. A seguir, centrou-se no MERCOSUL e na integração regional nas relações de trabalho, enfocando as principais normativas do bloco, bem como questões pontuais no Brasil, na Argentina e na Venezuela que ameaçam a integração regional laboral. 
Enfim, o presente artigo almejou contribuir para o enriquecimento das discussões sobre o trabalho digno em tempos obscuros de globalização e seus reflexos no processo de integração regional do MERCOSUL em face do possível esgotamento do regionalismo pós-liberal no século XXI.

\section{A CONCEPÇÃO DE TRABALHO DIGNO E SUA PROTEÇÃO JURÍDICA}

O trabalho do homem não se confunde com a atividade exercida pelos animais de modo instintivo para sobreviver, pois ao final do processo do labor, surge um resultado que já estava arquitetado idealmente na mente humana. Logo, "o trabalho que ultrapassa a mera atividade instintiva é assim a força que criou a espécie humana e a força pela qual a humanidade criou o mundo como conhecemos" (BRAVERMAN, 1980, p. 53).

O trabalho não deve ser considerado como mercadoria e o trabalhador visto apenas como instrumento integrante do sistema capitalista de produção, embora seja esta a concepção dominante ancorada numa visão economicista da sociedade. Então, o valor do trabalho humano deve ser considerado além dos aspectos puramente econômicos, com um bem jurídico necessário para a existência digna do trabalhador; deve ser visto à luz da matriz filosófica que o considera sob um prisma ÉTICO.

Battaglia (1958, p. 22-23) considera que todo trabalho para ser ético deve estar em consonância com os limites impostos pela própria dignidade humana. O trabalho humano é realidade poliédrica captada parcialmente pelas diferentes Ciências (Física, Biologia, Economia etc.), mas a Filosofia os unifica numa noção integral. Portanto, o trabalho digno está ancorado na ideia de dignidade humana do trabalhador, sendo compreendido sob dois aspectos (MARTINS, 2017, p. 41-42):

a) o intrínseco (subjetivo): como atributo pessoal e psíquico inerente ao ser humano, por exemplo, a satisfação pessoal do trabalhador em realizar determinada atividade; a sensação de ser útil para a comunidade em que vive; ser merecedor de respeito e consideração por parte do Estado e dos particulares; ser realmente livre para escolher o seu trabalho etc.;

b) o extrínseco (objetivo): representando as condições materiais previstas nas normas em geral reguladoras do ato de trabalhar, tais como: remuneração adequada e justa, sem discriminação de qualquer natureza; limite máximo e mínimo de duração da jornada de trabalho (diária e semanal); normas de higiene e segurança relacionadas ao meio ambiente do trabalho e à proteção da maternidade; concessão de férias, repouso semanal e feriados remunerados; licenças médicas em geral; normas proibitivas do trabalho infantil e do trabalho escravo etc. 
Assim, o trabalho digno inclui, as condições materiais objetivas (extrínsecas) em que o trabalho é realizado concomitantemente com as condições subjetivas (intrínsecas), pois ambas atendem ao princípio e valor da dignidade humana, integrando a própria condição humana do trabalhador. O trabalho digno é o gênero e o trabalho decente seria a espécie ${ }^{4}$.

Na condição de bem jurídico, o trabalho digno está tutelado no sistema global ONU, destacando-se a Declaração Universal dos Direitos Humanos (1948) que estabeleceu o direito ao trabalho, à livre escolha de emprego, a condições justas e favoráveis de trabalho e à proteção contra o desemprego (art. XXIII); direito a uma remuneração justa e satisfatória compatível com a dignidade humana (art. XXIV); direito a organizar sindicatos e a neles ingressar; direito a repouso e lazer, inclusive a limitação razoável das horas de trabalho e a férias remuneradas etc. (art. XXV) (USP, 2019). O Pacto Internacional dos Direitos Econômicos, Sociais e Culturais (1966) nos arts. $6^{\circ}$ a $9^{\circ}$ reconheceu à pessoa humana o direito de usufruir condições dignas, equânimes e favoráveis de trabalho, individual e coletivamente (USP, 2019).

Por sua vez, o sistema da OIT possui regras e princípios que tutelam em específico os direitos laborais, buscando o aperfeiçoamento das relações entre trabalho e capital. A partir de 1998, com a aprovação da Declaração relativa aos Princípios e Direitos Fundamentais no Trabalho, a OIT estabeleceu quatro áreas prioritárias de atuação para a concretização dos direitos humanos trabalhistas, a saber: liberdade sindical e reconhecimento efetivo do direito de negociação coletiva; eliminação de todas as formas de trabalho forçado ou obrigatório; abolição efetiva do trabalho infantil e eliminação da discriminação em matéria de emprego e ocupação (USP, 2019). Logo, a OIT propõe a implementação do trabalho decente entendido como o "trabalho adequadamente remunerado, exercido em condições de liberdade, equidade e segurança, capaz de garantir uma vida digna" (USP, 2019).

A ratificação das convenções da OIT pelos Estados mercosulistas ou mesmo de outros tratados e pactos internacionais de direitos humanos $\underline{\text { não significa }}$ que está ocorrendo a efetiva implementação de melhores condições de trabalho seja de forma individualizada por país, seja conjuntamente no âmbito da integração regional.

\footnotetext{
4 Embora a OIT e alguns juristas utilizem como sinônimo 'trabalho decente' e 'trabalho digno', entende-se que não o são. Segundo Brito Filho (2004, p. 61-62), “trabalho decente, então, é um conjunto mínimo de direitos do trabalhador que corresponde: à existência de trabalho; à liberdade de trabalho; à igualdade no trabalho; ao trabalho com condições justas, incluindo a remuneração, e que preservem sua saúde e segurança; à proibição do trabalho infantil; à liberdade sindical; e à proteção contra os riscos sociais".
} 
Então, apesar da ampla tutela jurídica do trabalho digno e dos direitos humanos trabalhistas, há notória dificuldade na sua concretização nos Estados mercosulistas, consoante problemática atinente aos direitos humanos que Bobbio (2004, p. 43, grifo do autor) já anteviu, pois "o problema fundamental em relação aos direitos do homem, hoje, não é tanto o de justificá-los, mas o de protegêe-los. Trata-se de um problema não filosófico, mas político". Segundo a OIT, "muitos países das Américas enfrentam sérios problemas com relação ao respeito e à aplicação efetiva dos princípios e direitos fundamentais no trabalho e da legislação trabalhista em geral" (OIT, 2019).

Portanto, o aprofundamento da integração social no MERCOSUL se mostra urgente mediante a adoção de políticas públicas comuns e articuladas entre os Estados-partes, mas há problemas internos profundos que são graves empecilhos para o avanço do projeto integracionista na seara laboral, como será pontuado a seguir.

\section{A INTEGRAÇÃO REGIONAL NO MERCOSUL E OS REVESES NA TUTELA LABORAL - REFLEXÕES ATUAIS SOBRE ARGENTINA, BRASIL E VENEZUELA}

À luz do regionalismo aberto, o Mercado Comum do Sul (MERCOSUL) ${ }^{5}$ assumiu, desde sua criação pelo Tratado de Assunção (1991), a condição de aliança comercial com vistas a dinamizar a economia regional, tendo o desafio de sua conversão, em longo prazo, em mercado comum com a implantação da livre circulação de bens, serviços, pessoas e capitais. Atualmente, este bloco é uma União Aduaneira ${ }^{6}$ imperfeita, contemplando uma Tarifa Externa Comum (TEC).

A integração regional essencialmente direcionada para os aspectos comerciais negligenciou as assimetrias estruturais e o déficit social que se acentuou nos países da América Latina ao longo da década de 1990. As crises econômicas mundiais que se seguiram a partir de 2000, em especial nos países emergentes, também acentuaram os efeitos perversos da

\footnotetext{
5 Em 04/07/2006, a República Bolivariana da Venezuela assinou o Protocolo de Adesão ao MERCOSUL, integrando o bloco em 12/08/2012. Em 07/12/2012, o Estado Plurinacional da Bolívia também assinou protocolo de adesão, estando em curso o processo para adquirir a condição de Estado-parte.

6 Segundo Balassa (1961, p. 13), a União Aduaneira "[...] implica, além da supressão das discriminações no que se refere aos movimentos de mercadorias no interior da união, a igualização dos direitos em relação ao comércio com países não membros". Haveria o estabelecimento de uma política comercial comum, juntamente com uma tarifa externa comum (TEC), seriam mantidas as instituições de cunho intergovernamental, mas se buscaria o aprofundamento das relações comunitárias.
} 
globalização econômica excludente e neoliberal, aprofundando as desigualdades sociais e regionais nos países latino-americanos.

Nesse diapasão, iniciou-se na América Latina um "giro à esquerda no âmbito político ou Onda Rosa" (MENDONÇA JÚNIOR, 2014, p. 20) a partir da ascensão ao poder de governos mais alinhados com a esquerda, tais como: Venezuela (1998), Brasil (2002 e 2006), Argentina (2003, 2008 e 2011), Uruguai (2004), Bolívia (2005), Equador (2006), Paraguai (2008) e Peru (2011) os quais rejeitaram as medidas de ajuste propostas pelo Consenso de Washington. Assim, tais governos buscaram maior inserção social dos povos, notadamente com o reposicionamento de indígenas e campesinos, almejando a redefinição das ações e políticas estatais. Esta fase do regionalismo latino-americano, cunhada de regionalismo pós-liberal, ganhou impulso após a V Cúpula das Américas na Colômbia, em Cartagena, em abril de 2012, possuindo especificidades:

A diferencia de la década precedente, signada por la narrativa neoliberal asociada al llamado "Consenso de Washington", junto con la reducción del rol del Estado a favor de un protagonismo de los actores del mercado, la década actual se ha caracterizado, de acuerdo a algunos análisis, por tres "retornos" distintivos, $\underline{\boldsymbol{e l}}$ "retorno" a un fortalecimiento del Estado; el "retorno" a la politización de las relaciones regionales, y el "retorno" a una agenda desarrollista marcadamente asociada a un nuevo impulso de una agenda social y de una serie de políticas consecuentes por parte del Estado, tanto en el ámbito específicamente social como en las esferas económica y política. [...] (SERBIN; MARTÍNEZ; RAMANZINI JÚNIOR, 2012, p. 11-12, grifo nosso).

A ampliação da agenda integracionista é necessária além dos aspectos comerciais, em especial nas questões sociais e laborais. No tocante a integração regional nas relações de trabalho no MERCOSUL, foi aprovada, em 1998, a Declaração Sociolaboral do MERCOSUL que previu vários direitos, destacando-se (MERCOSUL, 2019): não discriminação (art. $1^{\circ}$ ): promoção da igualdade (arts. $2^{\circ}$ e $3^{\circ}$ ); proteção aos trabalhadores migrantes e fronteiriços (art. $4^{\circ}$ ); eliminação do trabalho forçado (art. $5^{\circ}$ ); tutela do trabalho infantil e de menores (art. $6^{\circ}$ ); seguridade social (art. 19) etc. Esta declaração não é um tratado internacional e nem foi incorporada às ordens jurídicas internas dos Estados-Partes, não possuindo força normativa vinculante e coercitiva para os Estados mercosulistas, logo, não se incluiu entre as fontes jurídicas do bloco (art. 41 do Protocolo de Ouro Preto - $\mathrm{POP}^{7}$ ).

\footnotetext{
7 Art. 41 As fontes jurídicas do MERCOSUL são: I - o Tratado de Assunção, seus protocolos e os instrumentos adicionais ou complementares; II - os acordos celebrados no âmbito do Tratado de Assunção e seus protocolos; III - as Decisões do Conselho do Mercado Comum, as Resoluções do Grupo Mercado Comum e as Diretrizes da Comissão do MERCOSUL, adotadas deste a entrada em vigor do Tratado de Assunção (MERCOSUL, 2019).
} 
Em 17 de julho de 2015, na 48 Cúpula Social do MERCOSUL, houve a aprovação de Nova Declaração Sociolaboral (MERCOSUL, 2019), "atualizando" a de 1998. Apesar do significativo avanço que esta "nova" declaração poderia imprimir às relações de trabalho firmadas no bloco, ela também não possui força coercitiva e vinculante de tratado internacional, mantendo a mesma condição jurídica da Declaração de 1998 e, até o momento, apresentou os mesmos efeitos inócuos de sua predecessora.

Para o avanço da integração regional trabalhista no MERCOSUL, houve a aprovação do Acordo Multilateral de Seguridade Social e seu Regulamento Administrativo pela Decisão n ${ }^{\text {o }}$ 19/1997 do Conselho do Mercado Comum (CMC) que busca assegurar os mesmos direitos e obrigações perante a Previdência Social aos trabalhadores que tenham prestado serviços nos Estados-partes do MERCOSUL. As contribuições previdenciárias vertidas ao sistema de seguridade social pelo trabalhador, em qualquer dos Estados-partes, acumulam-se como se tivessem sido realizadas no mesmo país, havendo a totalização dos períodos de seguro ou de contribuição (art. $7^{\circ}$ da Decisão no 19/1997, CMC) (MERCOSUL, 2019). Logo, os períodos de seguro ou contribuição cumpridos em quaisquer dos Estados-partes serão considerados para efeito de concessão dos benefícios previdenciários (velhice, invalidez, morte etc.).

A Decisão no 28/2002 do CMC aprovou o Acordo sobre Residência de Nacionais dos Estados-partes do MERCOSUL, da República da Bolívia e da República do Chile ${ }^{8}$. Este acordo permitiu que o nacional de um dos Estados-partes do MERCOSUL, que deseje residir noutro Estado-parte, obtenha residência legal temporária de até dois anos mediante a comprovação de sua nacionalidade e a apresentação de documentos às autoridades migratórias, tais como: passaporte válido, cédula de identidade, certidão negativa de antecedentes judiciais etc. (MERCOSUL, 2019). Assim, a nacionalidade de um dos países do bloco seria o critério primordial para a concessão da residência legal que permitiria a pessoa trabalhar e estudar. Este pacto permitiria que o migrante, obtendo a residência temporária, estivesse habilitado ao trabalho em igualdade de condições com os nacionais daquele país onde tenha obtido a residência, cumprindo as disposições específicas da legislação do trabalho do local.

Em 2014, foi firmado o Acordo de Complementação ao "Acordo de Recife" em Matéria Migratória aprovado pela Decisão n ${ }^{\circ}$ 18/2014 do CMC. A fim de facilitar o comércio na região e o fluxo migratório foram estabelecidas outras modalidades de controle integrado migratório

\footnotetext{
8 Houve a adesão posterior do Peru (Decisão no 04/2011 do CMC), do Equador (Decisão n ${ }^{\circ}$ 21/2011 do CMC) e da Colômbia (Decisão nº 20/2012 do CMC).
} 
como o controle integrado simultâneo e o controle integrado por reconhecimento recíproco de competências $\left(\operatorname{art.} 5^{\circ}\right) . \mathrm{O}$ art. 10 estabeleceu a cooperação entre os Estados-partes para a implementação desses controles integrados, de modo que as autoridades migratórias prestarão mutuamente a colaboração necessária para o exercício de suas funções (MERCOSUL, 2019). Porém, tais medidas se direcionam a facilitação do comércio sub-regional mercosulista ao invés da proteção aos trabalhadores migrantes, demonstrando o descaso com a questão social envolvida na migração de pessoas no bloco em busca de condições de labor mais dignas.

Ademais, sob a influência do regionalismo pós-liberal, o bloco mercosulista buscou a ampliação de sua agenda social com a criação, em 2005, do Fundo para a Convergência Estrutural do MERCOSUL (FOCEM) a fim de financiar projetos para melhorar a infraestrutura da região, impulsionando a produtividade econômica dos Estados-Partes e o desenvolvimento social. Em 2007, foi criado o Instituto Social do MERCOSUL - ISM (Decisão do Conselho do Mercado Comum no 03/07) com sede em Assunção no Paraguai, Em 2009, criou-se o Instituto de Políticas Públicas em Direitos Humanos do MERCOSUL IPPDH (Decisão do Conselho do Mercado Comum no 14/09) com sede em Buenos Aires na Argentina e, no intuito de fortalecer a democracia e a participação política na região, criou-se, em 2005, o Parlamento do MERCOSUL (PARLASUL) (MERCOSUL, 2019).

Entretanto, quando se analisa a integração regional nas relações de trabalho, não se vislumbram significativos avanços no MERCOSUL, pois inexiste até o presente momento políticas públicas comuns e articuladas entre os Estados-partes orientadas para o fomento ao trabalho, a proteção ao desemprego e aos trabalhadores migrantes. $\mathrm{O}$ direito originário do MERCOSUL - constituído pelo Tratado de Assunção, o Protocolo de Ouro Preto e o Protocolo de Olivos - não tutela os direitos sociais dos trabalhadores e nem a solução de controvérsias na seara laboral. Não há nenhum regulamento ou normativa comunitária sobre os direitos sociais trabalhistas e os mecanismos para sua concretização conjunta no bloco, havendo apenas a tomada de ações e decisões de modo individual por cada Estado-parte, sobretudo na implementação da Agenda de Trabalho Decente proposta pela Organização Internacional do Trabalho (OIT) aos seus membros, incluindo o Brasil, a Argentina, o Paraguai, o Uruguai e a Venezuela.

O MERCOSUL possui caráter intergovernamental na medida em que as decisões só podem ser tomadas através do consenso de todos os Estados-partes, o que dificulta os avanços institucionais, inclusive para a adoção de ações e políticas públicas comuns em especial na seara 
laboral. Esta falta de independência nas tomadas de decisões também impede a consolidação no bloco do direito comunitário, havendo, apenas, normas incipientes que se aproximam do direito de integração. Segundo o art. $2^{\circ}$ do Protocolo de Ouro Preto (MERCOSUL, 2019), são órgãos com capacidade decisória no MERCOSUL, de natureza intergovernamental, o Conselho do Mercado Comum (CMC), o Grupo Mercado Comum (GMC) e a Comissão de Comércio (CCM).

A fim de incorporar esses atos normativos (resoluções, decisões e diretrizes/propostas) ao direito interno dos Estados-partes do MERCOSUL, o art. 40 do POP dispõe sobre o procedimento a ser realizado (MERCOSUL, 2019): a) uma vez aprovada a norma, os Estadospartes adotarão as medidas necessárias para a sua incorporação ao ordenamento jurídico nacional e comunicarão as mesmas à Secretaria Administrativa do MERCOSUL; b) quando todos os Estados-partes tiverem informado sua incorporação aos respectivos ordenamentos jurídicos internos, a Secretaria Administrativa do MERCOSUL comunicará o fato a cada Estado-parte e c) as normas entrarão em vigor simultaneamente nos Estados-partes trinta dias após a data da comunicação efetuada pela Secretaria Administrativa do MERCOSUL, logo, dentro deste prazo, eles darão publicidade do início da vigência das referidas normas por intermédio de seus respectivos diários oficiais.

$\mathrm{O}$ art. 42 do POP estabelece que as normas emanadas dos órgãos do MERCOSUL Conselho do Mercado Comum, o Grupo Mercado Comum e a Comissão de Comércio previstos no art. $2^{\circ}$ - terão caráter obrigatório e deverão quando necessário, ser incorporadas aos ordenamentos jurídicos nacionais mediante os procedimentos previstos pela legislação de cada país (MERCOSUL, 2019). Esta disposição normativa concede significativa margem de discricionariedade aos Estados-partes na incorporação das normas oriundas do MERCOSUL e, ainda, conflita com as previsões normativas dos artigos $9^{\circ}, 15,20,40$ e 41 do POP (MERCOSUL, 2019), enfraquecendo o processo de integração regional ao não impor aos Estados mercosulistas a obrigatoriedade absoluta de transposição das normas do bloco para o seu direito interno.

Portanto, a concessão pelo próprio Protocolo de Ouro Preto de discricionariedade aos Estados-partes para a incorporação total ou parcial do direito produzido no âmbito do MERCOSUL ao seu direito interno concomitantemente com o sistema intergovernamental de tomada de decisões, cerceia o pleno desenvolvimento da integração regional mercosulista, inclusive para a adoção de ações e políticas públicas na seara laboral, impedindo a construção 
de normas comunitárias e instituições supranacionais no bloco e, assim, favorecendo a predominância de interesses nacionais e locais dos Estados em detrimento do processo integracionista.

Somado a isso, o MERCOSUL está passando por grave crise institucional decorrente de acontecimentos de diversas ordens. Sob os ditames da globalização neoliberal, a ascensão de governos mais alinhados à direita nos Estados-Partes do bloco está cerceando o seguimento das ações e políticas sociais que haviam se iniciado sob a influência do regionalismo pós-liberal que, aparentemente, se esgotou.

No âmbito dos Estados-Partes, houve as eleições presidenciais com a vitória da direita conservadora no Paraguai com Horacio Cartes (2013) e seu sucessor Mario Abdo Benítez (2018); de Mauricio Macri na Argentina (2015), estando previsto para 27 de outubro de 2019 novas eleições presidenciais e, ainda, a vitória da oposição ao chavismo nas eleições para o Poder Legislativo venezuelano (2015). Além disso, ocorreu a suspensão da Venezuela do MERCOSUL, em agosto de 2017, por "ruptura da ordem democrática" pelo governo de Nicolas Maduro com fundamento nos arts. $4^{\circ}$ a $6^{\circ}$ do Protocolo de Ushuaia sobre Compromisso Democrático (MERCOSUL, 2019), aprofundando as instabilidades no bloco.

Ademais, a partir de 2014, as turbulências no cenário político brasileiro culminaram com a chegada ao poder, em 2016, do Presidente Michel Temer cujo governo (2016-2018) careceu de legitimidade jurídico-política culminando com a vitória da direita conservadora ao eleger Jair Bolsonaro para a Presidência da República (2019-2022). Em poucos meses no poder, este governo já demonstrou que foi eleito para atender aos anseios do capital global mediante a adoção de medidas de cunho neoliberal e restritivas aos direitos sociais como, por exemplo, cortes orçamentários nas verbas da educação pública, liberalização do uso de armas mediante decreto de natureza inconstitucional, proposta de reforma previdenciária semelhante ao caso chileno etc.

Então, o desmonte dos direitos laborais, ocorrido nas últimas décadas sob a influência do Consenso de Washington, agora se agrava pelo fortalecimento de governos latinoamericanos mais alinhados com a globalização neoliberal. Os governos de "esquerda" se perderam numa série de escândalos de corrupção, possibilitando “[...] la elección de Maurício Macri en Argentina, los golpes de Estado en Paraguay y en Brasil, y la elección de Donald Trump en los Estados Unidos, para citar solamente algunos ejemplos [...]" (DUDIUK; 
PRADO, 2018, p. 14), sendo o 'giro' à direita conservadora no continente latino-americano que impulsiona atualmente a desconstrução dos direitos sociais e laborais.

É necessário evidenciar que a institucionalização do Direito do Trabalho no Brasil teve início em 1930 com a ascensão de Getúlio Vargas ao poder, mas foi se aperfeiçoando até 1945, havendo a maior tutela jurídica dos direitos sociais e laborais. Recentemente, atendendo aos anseios do capitalismo financeiro global, houve a "reforma" trabalhista (Lei $n^{\circ}$ 13.467/2017) que alterou vários artigos da Consolidação das Leis do Trabalho (Decreto-lei no 5.452/1943) no intuito de esvaziar os direitos sociais laborais conquistados pelos cidadãos trabalhadores nos últimos séculos.

À título exemplificativo, no Direito Individual do Trabalho, destaca-se o contrato de trabalho intermitente (art. $443, \S 3^{\circ}$ da CLT) que possui jornada de trabalho e salário variáveis (BRASIL, 2019), compreendendo períodos de atividades e inatividades não previamente estabelecidos entre o empregado e o empregador - independentemente do ramo da atividade econômica -, causando total incerteza aos obreiros se o seu trabalho será requisitado ou, ainda, o valor efetivo da remuneração recebida ao final do mês, violando o princípio tutelar da proteção laboral.

Outra modificação decorrente da "reforma" foi o termo anual de quitação do contrato de trabalho (art. 507-B da CLT) que facultou aos empregados e empregadores, na vigência ou não do contrato de trabalho, dar quitação anual das obrigações trabalhistas devidas (BRASIL, 2019). É notório que os empregados, na condição de parte hipossuficiente da relação empregatícia, serão compelidos à assinatura anual deste termo de quitação das verbas trabalhistas a fim de manterem seus postos de trabalho, principalmente em razão do número expressivo de desempregados atualmente existente no país, ainda que discordem dos valores a serem quitados ou na pendência de obrigações trabalhistas não pagas. Logo, caberá ao empregado hipossuficiente a prova da ocorrência de possível erro, dolo ou coação na assinatura deste termo de quitação, estimulando a proliferação de abusos e práticas ilícitas por parte daqueles empregadores que agem de má-fé.

No campo do Direito Coletivo do Trabalho, a "reforma" promoveu o enfraquecimento dos sindicatos, muito ao contrário do que foi alardeado, pois tornou facultativa a cobrança da contribuição sindical sem outra contrapartida financeira (art. 579, CLT); permitiu a realização de banco de horas, prorrogação e compensação de jornada (art. 59, CLT) e jornada de trabalho 
12x36 (art. 59-A, CLT) por acordo individual, esvaziamento a atuação sindical; extinguiu a homologação sindical das rescisões contratuais de empregados com mais de um ano de vigência de contrato de trabalho pela revogação do $\S 1^{\circ}$ do art. 477, CLT; dispensou a autorização prévia do sindicato para as dispensas imotivadas individuais, plúrimas ou coletivas (art. 477-A, CLT), dentre outras situações (BRASIL, 2019).

Em síntese, vivencia-se no Brasil etapa sombria de desmonte da estrutura de bem-estar social e de direitos sociais, principalmente no trabalho, que vem sendo empreendida sob os auspícios da globalização econômica neoliberal que está esvaziando e anulando a dignidade da pessoa humana em prol de interesses das elites econômicas e políticas que estão no poder.

Na Argentina a situação de desmonte dos direitos laborais também está presente. $\mathrm{O}$ Direito do Trabalho consolidou-se no início século XX sob a influência das lutas operárias por condições de trabalho mais dignas. Segundo Antunes (2011, p. 23), em 1943, Juan Domingo Perón assumiu a Secretaria de Trabalho, sendo:

[...] linha divisória na relação entre o Estado e o movimento operário, por meio de um complexo processo de apoio e cooptação que tinha como contrapartida a melhoria das condições de vida da classe trabalhadora, bem como a institucionalização dos direitos sociais do trabalho.

A legislação laboral protetiva dos trabalhadores na Argentina foi sufocada com o golpe militar de 1976, retomando sua evolução com as eleições democráticas do Presidente Raúl Alfonsín, em 1983, com a ajuda da Confederação Geral do Trabalho (CGT) que manteve relacionamento com os governos seguintes, inclusive o de Carlos Menem (TOPET, 2019).

Atualmente, a legislação laboral argentina é esparsa e fragmentada, destacando-se principalmente a Lei de Contrato de Trabalho (LCT): Lei no 20.744/1974 que previu as modalidades de contratação. Há também a Lei n 11.544/1929 de Jornada de Trabalho, a Lei $n^{\circ}$ 24.557/1995 de Riscos do Trabalho, a Lei n 24.013/91 sobre Emprego, a Lei n 25.013/1998 de Reforma Laboral, a Lei $n^{\circ}$ 25.877/2004 de Regime Laboral etc. (ARGENTINA, 2019). De acordo com Villarino (2012, p. 17):

A regra geral no Direito Trabalhista argentino é que o contrato de trabalho é celebrado por tempo indeterminado. Nesse sentido, o ônus da prova de que o contrato não foi celebrado por tempo indeterminado cai sobre o empregador. O contrato de trabalho por tempo indeterminado não exige formalidade de celebração alguma, podendo ser celebrado, ainda, sem contrato por escrito e ficando configurado pelo mero cumprimento de tarefas. 
Desde a década de 1990, o direito laboral argentino também está sofrendo reformas flexibilizadoras para a redução de direitos trabalhistas como a Lei $n^{\circ}$ 25.877/2004 que introduziu aspectos flexibilizadores na legislação trabalhista argentina, precarizando o contrato de trabalho e reduzindo a proteção do trabalhador como, por exemplo, ao estabelecer período de prova de três meses para os contratos por prazo indeterminado (art. 92 bis da LCT). Qualquer das partes poderá extinguir a relação de trabalho durante esse lapso temporal sem justificar a causa, sem direito a indenização pela extinção contratual, porém com obrigação de pré avisar a parte contrária (arts. 231 e 232 da LCT) (ARGENTINA, 2019).

Além dos contratos por prazo indeterminado (mais benéficos aos trabalhadores), a legislação laboral argentina permitiu a realização de contratos a tempo parcial (art. 92 ter da LCT), contratos por prazo determinado ou prazo fixo (arts. 93 a 95 da LCT), contratos de trabalho de temporada (arts. 96 a 98 da LCT), contratos de trabalho eventuais (arts. 99 a 100 da LCT) e contratos de trabalho de grupo ou por equipes (arts. 101 a 102 da LCT) (ARGENTINA, 2019).

Tais modalidades contratuais possuem como características gerais a contratação dos trabalhadores por períodos mais curtos de tempo, apresentam situações de imprevisibilidade extremamente desfavoráveis aos obreiros, que assumem os riscos das atividades econômicas ao invés de seus empregadores, consubstanciando-se em contratos precários. Sobre o trabalho eventual, a Lei $\mathrm{n}^{\circ} 24.013 / 1991$ substituiu o art. 99 da LCT pelos arts. 68 a 74 (ARGENTINA, 2019), trazendo maior flexibilidade à contratação por esta modalidade. Segundo Barros (2011, p. 153), esta lei:

[...] exige o redimensionamento do Ministério do Trabalho e da Seguridade Social, e a diminuição que autoriza as contribuições patronais em relação a certas modalidades contratuais, exacerba a crise da Seguridade Social, acelerando o esgotamento do sistema [...]. O autor Slavin ${ }^{9}$, nas duras críticas à lei em causa, acentua que a ideia central de criar novos empregos não pode ser alcançada por meio de leis, mas sim pela formulação e desenvolvimento de uma adequada política de estímulo ao emprego, buscando a máxima utilização dos recursos humanos e econômicos e não pelas vias escolhidas, que mais provavelmente levarão o empregador a substituir seus empregados permanentes por trabalhadores precários, de custo trabalhista mais baixo, desconhecendo o princípio tutelar da legislação do trabalho.

Desse modo, a regulação contratual do trabalho na Lei de Contrato de Trabalho argentina e suas posteriores alterações objetivaram a redução dos direitos sociais laborais,

\footnotetext{
${ }^{9}$ SLAVIN, Luis Pablo. Análisis crítico de la ley nacional de empleo. Buenos Aires: Depalma, 1992, p. 112-113 [nota do autor].
} 
diminuindo a intervenção do Estado e concedendo maior autonomia e liberdade aos empregadores para contratar os trabalhadores por períodos mais exíguos sem a corresponde garantia de manutenção do emprego, de salário e de previsibilidade no exercício da jornada de trabalho.

Ademais, há perspectivas de aprovação de uma "reforma" trabalhista na Argentina inspirada no modelo brasileiro - pelo Presidente Mauricio Macri ${ }^{10}$ que já vem adotando medidas em favor exclusivamente do empresariado como a redução do valor de multas de empresas que contratem trabalhadores de forma irregular, dificultando o desenvolvimento de agendas social e laboral para o MERCOSUL.

Tal situação certamente se coaduna com os ataques impostos ao Direito do Trabalho pelo capitalismo financeiro global, pois, em desconformidade à promoção e garantia do trabalho digno, foram adotados " $[. .$.$] contratos de arrendamiento de servicios en lugar de contratos de$ trabajo, la supuesta contratación de trabajadores constituidos en 'empresas unipersonales' y diversas formas de subcontratación y tercerización [...]” (URIARTE, 2006, p. 08), expulsando o trabalhador da proteção das normas laborais.

Por seu turno, a Venezuela passa por profunda crise política com a vitória da oposição ao chavismo nas eleições legislativas, em 2015, que se agravou, a partir de janeiro de 2019, pela declaração de Juan Guaidó, então Presidente da Assembleia Nacional, como Presidente Interino do país, alegando que Nicolás Maduro fraudou as eleições para se manter no poder até 2025. A crise econômica também é grave porque se originou, inicialmente, da queda dos preços do petróleo a partir de 2014 no mercado internacional, pois era o principal produto que sustentava a economia venezuelana a qual se "desindustrializou" ao longo dos anos, ficando dependente da venda desta commodity no mercado internacional. O país também enfrenta inflação galopante e desabastecimento de produtos e alimentos para a população.

Tais situações agravaram a pobreza, a fome e o desemprego no país, impulsionando a migração de venezuelanos para outros países do Continente Latino-americano, principalmente

\footnotetext{
10 Segundo Borón (2019), “com o governo de Mauricio Macri, a Argentina passou por uma dupla involução. Por um lado, a transição de uma democracia capitalista limitada para um regime semi-autoritário, uma 'democradura'. Macrismo é um híbrido que, em diferentes proporções, dependendo do caso, combina certas características de uma ditadura com as formalidades de uma democracia puramente eleitoral. Por outro lado, uma segunda transição de um estado soberano para um semicolonial, pronto a obedecer aos mandatos emanados de Washington, alinhandose incondicionalmente com a política externa dos Estados Unidos e, recentemente, estabelecendo um aberrante cogoverno entre a Casa Rosada e o FMI”.
} 
o Brasil em razão de a Venezuela integrar o MERCOSUL desde 2012. Não se pode olvidar que a migração internacional representa o "tendão de Aquiles" no contexto da integração regional ao envolver diretamente a circulação de pessoas no bloco, sobretudo por razões econômicas, pois sempre ocorre o "deslocamento de contingentes humanos para áreas em que o sistema produtivo concentra maiores ou melhores oportunidades de emprego" (VESENTINI, 1997, p. 220). Quando se analisa a circulação de pessoas no MERCOSUL, verifica-se que há o predomínio da migração de trabalhadores que buscam melhores condições de vida e de trabalho do que possuem em seu país de origem, sobretudo por influência de facilidades advindas do processo de integração regional.

Segundo pesquisa realizada pelo Conselho Nacional de Imigração (CNIG, 2018), os migrantes venezuelanos são majoritariamente jovens ( $72 \%$ do total entre 20 e 39 anos), homens (63\%) e solteiros (54\%), sendo a crise econômica e política o principal motivo para emigrar, segundo $77 \%$ dos entrevistados. Os imigrantes venezuelanos apresentam bom nível de escolaridade, pois $78 \%$ possuem nível médio completo e $32 \%$ superior completo ou pósgraduação, mas apresentam pouco conhecimento da Língua Portuguesa e muitos não estudam o idioma (CNIG, 2018).

Com relação ao emprego, a pesquisa evidenciou que $60 \%$ dos migrantes venezuelanos possui alguma atividade remunerada, sendo $28 \%$ formalmente empregados. Eles atuam principalmente nos seguintes ramos de atividades: comércio (37\%), serviço de alimentação (21\%) e construção civil (13\%). Além disso, $51 \%$ dos trabalhadores migrantes recebem menos de um salário mínimo, $44 \%$ recebem entre um e dois salários mínimos e apenas $5 \%$ indicaram receber mais de dois salários mínimos. Mais da metade dos migrantes entrevistados $(54,2 \%)$ utilizam seus rendimentos para enviar remessas monetárias (de $\mathrm{R} \$ 100,00$ a $\mathrm{R} \$ 500,00$ ) para cônjuge e filhos na Venezuela com a finalidade de ajudar no sustento de seus familiares (CNIG, 2018).

Em face do caos social em que se encontram os migrantes venezuelanos no Estado de Roraima, o governo federal brasileiro estabeleceu medidas de assistência emergencial para o acolhimento dessas pessoas, alegando fluxo migratório provocado por crise humanitária. Porém, entende-se que tal situação não decorre simplesmente de uma crise humanitária localizada na Venezuela, mas tem origens mais profundas, sobretudo em razão da ausência de ações e políticas coordenadas e harmônicas entre os Estados-membros do MERCOSUL, desde as origens do bloco, para a implementação, de paulatina e efetiva, integração social e trabalhista. 
Em razão das assimetrias apontadas no âmbito do MERCOSUL e de seus Estados-Partes - principalmente Argentina, Brasil e Venezuela ora analisados -, há sérios entraves para avanço da integração regional das relações de trabalho, em especial para a concretização do trabalho digno.

\section{CONCLUSÃO}

A integração regional no MERCOSUL está inserta num contexto mais amplo de mudanças jurídicas, políticas e econômicas e nas relações internacionais ocorridas no cenário mundial a partir do século XX. Tal conjuntura concorreu para a progressiva inserção dos direitos humanos nas ordens jurídicas contemporâneas a fim de resguardar a pessoa humana e sua dignidade. A partir de 2012, o regionalismo pós-liberal influenciou os países latinoamericanos e o MERCOSUL no avanço da agenda social.

À luz do regionalismo pós-liberal, o MERCOSUL efetivou algumas ações para a ampliação de sua agenda social (criação do FOCEM, do ISM, do IPPDH, da UPS, do PARLASUL etc.), porém, a integração regional nas relações de trabalho não avançou no bloco. Na atualidade esta situação se agrava em razão do giro à direita adotado na maioria dos Estados-Partes do MERCOSUL com a implementação de reformas flexibilizadoras para a redução de direitos sociais e trabalhistas, em especial no Brasil e na Argentina.

A Venezuela está em profunda crise democrática e social impulsionando as pessoas a deixarem o país na condição de migrantes. Não se trata de crise humanitária, mas de crise com origens mais profundas no próprio processo de integração regional do MERCOSUL que não implementou ações e políticas coordenadas e harmônicas entre os Estados-membros para o avanço efetivo da integração social e trabalhista. Inexistem, até o momento, políticas públicas comuns e articuladas entre os Estados-Partes orientadas para o fomento ao trabalho, a proteção ao desemprego e aos trabalhadores migrantes associadas ao desenvolvimento econômico com equidade.

Não há nenhum regulamento ou normativa comunitária sobre os direitos sociais trabalhistas e os mecanismos para sua concretização conjunta no bloco, havendo apenas a tomada de ações e decisões de modo individual por cada Estado-parte em busca da concretização do trabalho digno e da Agenda de Trabalho Decente proposta pela OIT aos seus membros, o que inclui o Brasil, a Argentina, o Paraguai, o Uruguai e a Venezuela. Há também 
assimetrias na legislação trabalhista interna dos Estados-Partes do MERCOSUL (MARTINS, 2017, p. 147-175), inviabilizando a harmonização dessas normas para a regulamentação dos direitos sociais laborais, inclusive dos migrantes, dificultando a integração regional nas relações de trabalho.

Tais entraves são em parte explicados porque se conformou no MERCOSUL o sistema intergovernamental de tomada de decisões exigindo o consenso e a presença de todos os Estados-Partes, dificultando os avanços institucionais e impedindo a consolidação do direito comunitário fundamentado na supranacionalidade. Os Estados-Partes também não são obrigados a incorporarem as normas emanadas dos órgãos do MERCOSUL - Conselho do Mercado Comum, o Grupo Mercado Comum e a Comissão de Comércio -, havendo discricionariedade de cada Estado na transposição dessas normas ao seu direito interno.

O trabalho digno - enquanto direito humano - é indissociável do respeito à dignidade humana do trabalhador, devendo concretizado pelos Estados mercosulistas em políticas públicas de trabalho comuns e articuladas, inclusive com o auxílio dos particulares e da sociedade civil o fomento ao trabalho e a proteção do desemprego no bloco. Porém, esse trabalho digno expresso no sistema jurídico não consegue se efetivar no processo de integração regional do MERCOSUL.

Então, em razão das assimetrias apontadas no bloco mercosulista e entre seus EstadosPartes - principalmente Argentina, Brasil e Venezuela ora analisados -, há sérios entraves para avanço da integração regional das relações de trabalho. Tal situação vem se repetindo com frequência no contexto de outros processos de integração regional em função da globalização econômica neoliberal e da retomada de um "giro à direita" nos governos de vários países, inviabilizando a concretização do trabalho digno.

Enfim, são complexos os fatores que envolvem a questão do trabalho assalariado nas diversas partes do globo terrestre, mas, no intuito de enfrentar a globalização neoliberal que avança na América Latina, é imperioso o "transbordamento" do desenvolvimento econômico para as áreas sociais, principalmente envolvendo o trabalho humano e a migração de trabalhadores, no intuito de reduzir a pobreza e as desigualdades sociais rumo a uma integração regional mais solidária pautada, senão todo o processo se esvanecerá. 


\section{REFERÊNCIAS}

ARGENTINA. Información legislativa y documental. Disponível em: http://www.infoleg.gob.ar/. Acesso em: 19 abr. 2019.

ANTUNES, Ricardo. O continente do labor. São Paulo: Boitempo Editorial, 2011.

BALASSA, Bela. Teoria da integração econômica, 3. ed., trad. Maria Filipa Gonçalves e Maria Elsa Ferreira, Livraria Clássica Editora: Lisboa, 1961.

BARROS, Cassio Mesquita. Perspectivas do direito do trabalho no MERCOSUL. São Paulo: LTr, 2011.

BATTAGLIA, Felice. Filosofia do trabalho. Tradução de Luís Washington Vita e Antônio D’Elia, São Paulo: Saraiva, 1958.

BIELSCHOWSKY, Ricardo. Cinquenta anos de pensamento na CEPAL: uma resenha, in: BIELSCHOWSKY, Ricardo (Org.). Cinquenta anos de pensamento na CEPAL, v. 1, Rio de Janeiro: COFECON/Record, 2000, p. 13-68.

BRASIL. Consolidação das Leis do Trabalho. Disponível em: http://www.planalto.gov.br/ccivil_03/Decreto-Lei/Del5452.htm. Acesso em: 11 set. 2019.

BRAVERMAN, Harry. Trabalho e capital monopolista: a degradação do trabalho no século XX, trad. Nathanael C. Caixeiro, 2. ed., Rio de Janeiro: Zahar Editores, 1980.

BRITO FILHO, José Cláudio Monteiro de. Trabalho decente, São Paulo: LTr, 2004.

BOBBIO, Norberto. A era dos direitos, tradução de Carlos Nelson Coutinho, apresentação de Celso Lafer, nova ed., 5. reimpr., Rio de Janeiro: Campus Elsevier, 2004.

BORON, Atílio. As involuções da Argentina de Macri. Disponível em: http://www.vermelho.org.br/noticia/317235-1. Acesso em: 19 abr. 2019.

DUDIUK, Pedro e PRADO, Silvio. Introdução, in: AMARAL, Fernanda Pattaro [et. al.]. (Comp.). El desangramiento latinoamericano: un panorama político contemporáneo sobre la 
reorganización y la reconfiguración del estado neoliberal. Barranquilla: Corporación Universitaria Americana, 2018.

MARTINS, Juliane Caravieri. Trabalho digno e direitos humanos em tempos de globalização: perspectivas para a América Latina. Belo Horizonte: Arraes Editores, 2017.

MENDONÇA JÚNIOR, Wilson. O regionalismo pós-liberal na América do Sul, Revista Conjuntura Internacional, v. 11, n. 1, Belo Horizonte, 2014, p. 18-24.

MERCOSUL. Documentos e normativa. Disponível em: https://www.mercosur.int/pt-br/. Acesso em: 08 jul. 2019.

OIT. Trabalho decente nas Américas: uma agenda hemisférica (2006-2015). Disponível em: https://www.ilo.org/brasilia/publicacoes/WCMS_226226/lang--pt/index.htm. Acesso em: 17 jun. 2019.

PIRES, Julio Manuel e COSTA, Iraci del Nero da (Orgs.). O capital escravista-mercantil e a escravidão nas Américas, São Paulo: EDUC: FAPESP, 2010.

SERBIN, Andrés; MARTÍNEZ, Laneydi e RAMANZINI JÚNIOR, Haroldo (Coords.). El regionalismo "post-liberal" en América Latina y el Caribe: nuevos actores, nuevos temas, nuevos desafíos, Anuario de la Integración Regional de América Latina y el Gran Caribe, CRIES, Buenos Aires: Argentina, 2012.

USP. Biblioteca virtual de direitos humanos. Disponível em: http://www.direitoshumanos.usp.br/. Acesso em: 17 jun. 2019.

TOPET, Pablo Arnaldo. Breve historia del derecho del trabajo en la República Argentina. Disponível em: http://www.fundacion.uocra.org/documentos/recursos/articulos/Topet-Brevehistoria-del-derecho-del-trabajo-en-la-Republica-Argentina.pdf. Acesso em: 18 abr. 2019.

URIARTE, Oscar Ermida. La nueva legislación laboral uruguaya, IUSLabor, University Pompeu Fabra, Barcelona, n. 4, 2006, p. 01-09.

VILLARINO, Frederico. O direito do trabalho individual na Argentina, in: ZIMMERMANN, Lucia Vidigal (Org.). O direito do trabalho individual: Argentina, Brasil, Uruguai. São Paulo: LTr, 2012. 
VESENTINI, José Willian. Brasil: sociedade e espaço, São Paulo: Ática, 1997.

Recebido em: 23/11/2018

Aprovado em: 08/08/2019

Publicado em: 09/10/2019 